Tema: Metalurgia Secundária

\title{
CARACTERIZAÇÃO TÉCNICA DA CAMADA PROTETORA DE SILICATO DICÁLCICO EM PANELA DE AÇO DE REVESTIMENTO DOLOMÍTICO*
}

\section{Resumo}

O conhecimento sobre o comportamento do revestimento refratário dolomítico durante a etapa do refino de aço é fundamental para se atender às exigências técnicas de qualidade e o aumento da produção de aço. É particularmente importante que os mecanismos de corrosão dos refratários dolomíticos sejam bem compreendidos, principalmente, em operações de exceção, nas quais as exigências metalúrgicas causem forte dano ao revestimento, prejudicando não somente o desempenho do mesmo, mas também gerando um risco à segurança operacional. Este trabalho visa à caracterização técnica da camada protetora (coating) de silicato dicálcico $\left(\mathrm{C}_{2} \mathrm{~S}\right)$, a qual se origina da reação entre as escórias silicosas e os refratários dolomíticos. As amostras de coating foram caracterizadas quanto à composição química, fases formadas e microestrutura. Estudou-se uma panela retirada de operação, por dano aos refratários, retirando-se amostras de diferentes regiões. Em duas amostras, juntamente com $\mathrm{O}_{2} \mathrm{~S}$ e o periclásio, foi observado à presença de fases à base de silicato de baixa fusibilidade como a cuspidina, indicando que o coating foi atacado por uma escória com elevado teor de fluorita.

Palavras-chaves: Refratários dolomíticos; Coating; Corrosão; Aciaria.

\section{TECHNICAL CHARACTERIZATION OF PROTECTIVE LAYER OF DICALCIUM SILICATE IN STEEL LADLE WITH DOLOMITIC LINING}

\section{Abstract}

The knowledge about the behavior of the dolomitic refractory during steel refining step is essential to reach the technical requirements of quality and increased production of steel. It is particularly important that the mechanisms of corrosion of dolomitic refractories are well understood especially in operations exception, in which the metallurgical requirements cause serious harms to the lining, damaging not only its performance but also generates a risk to operational safety. This work aims the technical characterization of the protective layer ("coating") of dicalcium silicate $\left(\mathrm{C}_{2} \mathrm{~S}\right)$, which originates from the reaction between the siliceous slag and dolomitic refractories. The coating samples were characterized by chemical composition, phase formation and microstructure. It has studied a ladle withdrawn from operation due its refractories damage. Samples have been withdrawn from different regions of the ladle. In two samples, along with the $\mathrm{C}_{2} \mathrm{~S}$ and periclase was observed the presence of silicate-based phases with low melting point like cuspidine, indicating that the coating was attacked by a slag with a high content of fluorite Keywords: Doloma-C refractories; Coating; Corrosion; Factsage. 


\section{INTRODUÇÃO}

O conhecimento sobre o comportamento do refratário durante a etapa de refino secundário é fundamental para garantir não somente o alto desempenho do refratário, mas também para atender as exigências técnicas de qualidade do aço e segurança operacional.

É particularmente importante que os mecanismos de corrosão dos refratários dolomíticos sejam bem compreendidos, principalmente, em operações de exceção, nas quais as exigências metalúrgicas, como rápida dessulfuração do aço e/ou aumento da fase líquida na escória, causem forte dano ao revestimento, prejudicando não somente o desempenho do mesmo, mas também gerando um risco à segurança operacional. Por exemplo, em casos que o nível de enxofre fique muito alto no aço, torna-se necessário o aporte de considerável quantidade de fluorita.

A boa resistência às escórias apresentada pelos refratários doloma- $C$ deve-se à presença de $\mathrm{CaO}$ livre, não encontrado em outros materiais refratários de menor basicidade. Quando em contato com escórias básicas, não completamente saturadas em $\mathrm{CaO}$, a escória começa a dissolver o $\mathrm{CaO}$ do tijolo, formando um líquido de alta basicidade e viscosidade, até a formação de uma camada densa de silicato dicálcico $\left(\mathrm{C}_{2} \mathrm{~S}\right)$ [1]. A formação da fase $\mathrm{C}_{2} \mathrm{~S}\left(\mathrm{Tf}=2154^{\circ} \mathrm{C}\right)$ [2] na interface refratário-escória retarda a dissolução da fase $\mathrm{CaO}$ no tijolo pela ação da escória líquida, uma vez que a fina camada de $\mathrm{C}_{2} \mathrm{~S}$ (denominada coating) protege $\mathrm{o}$ refratário contra a penetração da escória.

A grande vantagem do coating de superfície é que a camada é formada através de uma reação química termodinamicamente favorável, com forte aderência no tijolo [1].

Após a formação do coating, a presença de óxidos como $\mathrm{Al}_{2} \mathrm{O}_{3}, \mathrm{FeO}$ e a fluorita podem dissolver o coating, formando fases mais fundentes, como aluminatos e silicatos de cálcio (como especificamente o óxido ferroso na formação da failita).

Além da dissolução, outro agravante para a perda do coating na face quente do tijolo dolomítico são as mudanças polimórficas que ocorrem durante o resfriamento. Quando a temperatura chega abaixo de $500^{\circ} \mathrm{C}$, a transformação de fase $\mathrm{C}_{2} \mathrm{~S}-\beta$ para $\mathrm{C}_{2} \mathrm{~S}$-y pode ocorrer, de acordo com a termodinâmica do processo, seguida por uma larga expansão volumétrica $(\sim 12 \%)$ [3]. Assim, o coating tende a se separar/desprender da face quente do tijolo. Este fenômeno pode ser visto quando a panela de aço é resfriada para manutenção mecânica ou refratária.

O polimorfismo do silicato dicálcico tem sido amplamente estudado devido à considerável importância deste composto nas indústrias de materiais refratários e de cimento [4].

A sequência atualmente mais aceita de transformações do $\mathrm{C}_{2} \mathrm{~S}$ apresenta cinco polimorfos e está ilustrada na Figura 1 [3].

O polimorfo de menor temperatura $\mathrm{C}_{2} \mathrm{~S}-\mathrm{\gamma}$, estável a temperatura ambiente, transforma-se, no aquecimento, a $800^{\circ} \mathrm{C}$, em $\mathrm{C}_{2} \mathrm{~S}-\alpha_{\mathrm{L}}$ e a $1160^{\circ} \mathrm{C}$, em $\mathrm{C}_{2} \mathrm{~S}-\alpha_{\mathrm{H}}$. O aquecimento superior a $1425^{\circ} \mathrm{C}$ produz o polimorfo $\mathrm{C}_{2} \mathrm{~S}-\alpha$. Já no resfriamento, a $670^{\circ} \mathrm{C}$, produz-se $\mathrm{C}_{2} \mathrm{~S}-\beta$ (metaestável), o qual não se forma durante o aquecimento a partir do polimorfo $\mathrm{C}_{2} \mathrm{~S}-\mathrm{\gamma}$. Por sua vez, o $\mathrm{C}_{2} \mathrm{~S}-\beta$, com resfriamento a temperaturas inferiores a $500^{\circ} \mathrm{C}$, converte-se de forma reconstrutiva e irreversível para $\mathrm{C}_{2} \mathrm{~S}-\gamma$.

$\mathrm{O}$ polimorfo $\mathrm{C}_{2} \mathrm{~S}-\beta$ apresenta estrutura monoclínica e se estabiliza pelo resfriamento rápido e pela incorporação de elementos menores em solução sólida, os quais distorcem a estrutura e impedem transformações polimórficas subsequentes. $O$

* Contribuição técnica ao 450 Seminário de Aciaria - Internacional, 25 a 28 de maio de 2014, Porto Alegre, RS, Brasil. 
mineral larnita, encontrado em auréolas de metamorfismo de contato em calcários, é análogo ao $\mathrm{C}_{2} \mathrm{~S}-\beta$.

$\mathrm{O}$ polimorfo $\mathrm{C}_{2} \mathrm{~S}-\mathrm{\gamma}$ cristaliza-se no sistema ortorrômbico, com estrutura análoga à do mineral olivina.

O conhecimento da seqüência de transformações de fases e das temperaturas em que estas ocorrem é de grande importância para a tecnologia cerâmica em geral. $A$ pulverização espontânea ocorre devido à transformação $\mathrm{C}_{2} \mathrm{~S}-\beta$ para $\mathrm{C}_{2} \mathrm{~S}-\gamma$ durante o resfriamento lento a uma temperatura entre 400 e $500^{\circ} \mathrm{C}$, que acarreta aumento de $\sim 12 \%$ em volume [3].

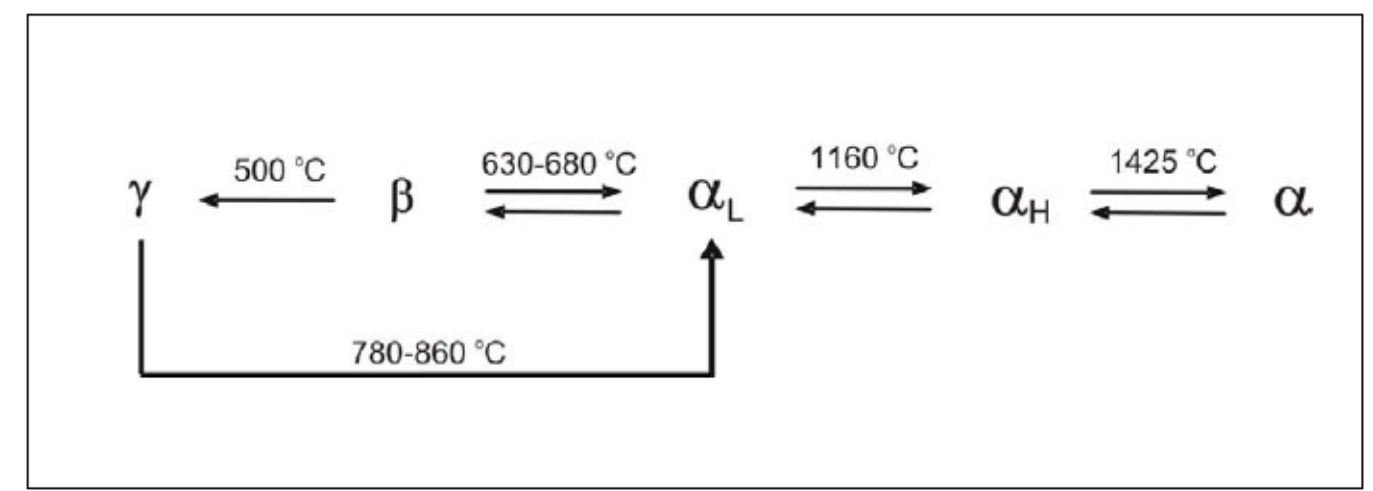

Figura 1. Temperaturas de transformações polimórficas do $\mathrm{C}_{2} \mathrm{~S}-\mathrm{Sob}$ pressão atmosférica [3].

Através da caracterização técnica da camada protetora (coating) o presente trabalho visa auxiliar à compreensão dos fatores químicos e termomecânicos que dissolvem ou desprendem o coating do tijolo refratário. Nesse sentido, pretende-se gerar informações que contribuam à adesão e manutenção do coating e, consequentemente, a aumentar a vida útil do revestimento refratário.

\section{MATERIAIS E MÉTODOS}

Inicialmente, procedeu-se com a caracterização de uma amostra de coating (camada protetora de silicato de dicálcico) padrão, denominada STD, retirada de uma panela em condições normais de processo, após atingir um número significativo de corridas, chegando ao fim de sua vida útil, sendo necessária a troca do revestimento. A amostra foi caracterizada com o auxílio das técnicas de difração de raios X (Philips X'Pert), fluorescência de raios X (espectrômetro Shimadzu XRF1800), microscopia eletrônica de varredura (MEV) e análise térmica (TGA/DTA851Mettler Toledo). Na análise por fluorescência os elementos são apresentados na forma de óxidos. Procedeu-se o estudo da sinterização e avaliação do comportamento das tensões térmicas durante o resfriamento através de um teste realizado em forno mufla. As amostras foram aquecidas a $1200^{\circ} \mathrm{C}$ com patamar de 30 minutos e retiradas durante o resfriamento natural, quando a temperatura do forno indicava $600^{\circ} \mathrm{C}$. Nesta temperatura, elas foram imediatamente fotografadas em câmera digital.

Finalizou-se o trabalho com estudo de caso do coating proveniente de uma panela retirada de operação, por dano aos refratários, na qual houve intensivo uso de fluorita para elevar a taxa de dessulfuração no Forno Panela. As amostras retiradas de diferentes pontos das panelas foram caracterizadas pelas técnicas descritas anteriormente, a fim de se avaliar o efeito da fluorita sobre o coating. Corpos-deprova de misturas de fluorita e coating $\left(\mathrm{C}_{2} \mathrm{~S}\right.$ retirado de uma panela em condições

\footnotetext{
* Contribuição técnica ao 45 Seminário de Aciaria - Internacional, 25 a 28 de maio de 2014, Porto Alegre, RS, Brasil.
} 


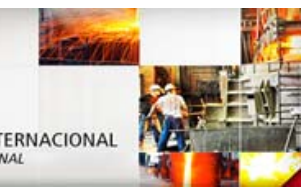

normais de operação) foram queimados em forno mufla a $1400^{\circ} \mathrm{C}$, com patamar de 30 minutos e atmosfera de ar, estudando-se a sinterabilidade das mesmas.

\section{RESULTADOS}

\subsection{Caracterização da Amostra Padrão do Coating (STD)}

Os principais óxidos presentes na amostra STD (Tabela 1) são: CaO (61,59\%) e $\mathrm{SiO}_{2}(32,48 \%)$. Os principais óxidos substituintes ou impurezas presentes nessa amostra são: $\mathrm{MgO}(3,41 \%), \mathrm{SO}_{3}(1,19 \%), \mathrm{Al}_{2} \mathrm{O}_{3}(0,58 \%)$ e $\mathrm{Fe}_{2} \mathrm{O}_{3}(0,71 \%)$. Segundo Gomes [5], em processos envolvendo o enxofre, o cristal de $\mathrm{C}_{2} \mathrm{~S}$ tende a concentrar parte desse composto em sua estrutura. Isto explica a presença significativa do $\mathrm{SO}_{3}$ na amostra STD. Por se tratar de uma análise por fluorescência de raios- $X$, os compostos identificados estão na forma de óxidos, como referido no item Materiais e Métodos.

Tabela 1. Composição química da amostra padrão

\begin{tabular}{ccccccc}
\hline Amostra (\%) & $\mathrm{CaO}$ & $\mathrm{SiO}_{2}$ & $\mathrm{MgO}$ & $\mathrm{SO}_{3}$ & $\mathrm{Al}_{2} \mathrm{O}_{3}$ & $\mathrm{Fe}_{2} \mathrm{O}_{3}$ \\
\hline $\mathrm{STD}$ & 61,59 & 32,48 & 3,41 & 1,19 & 0,58 & 0,71 \\
\hline
\end{tabular}

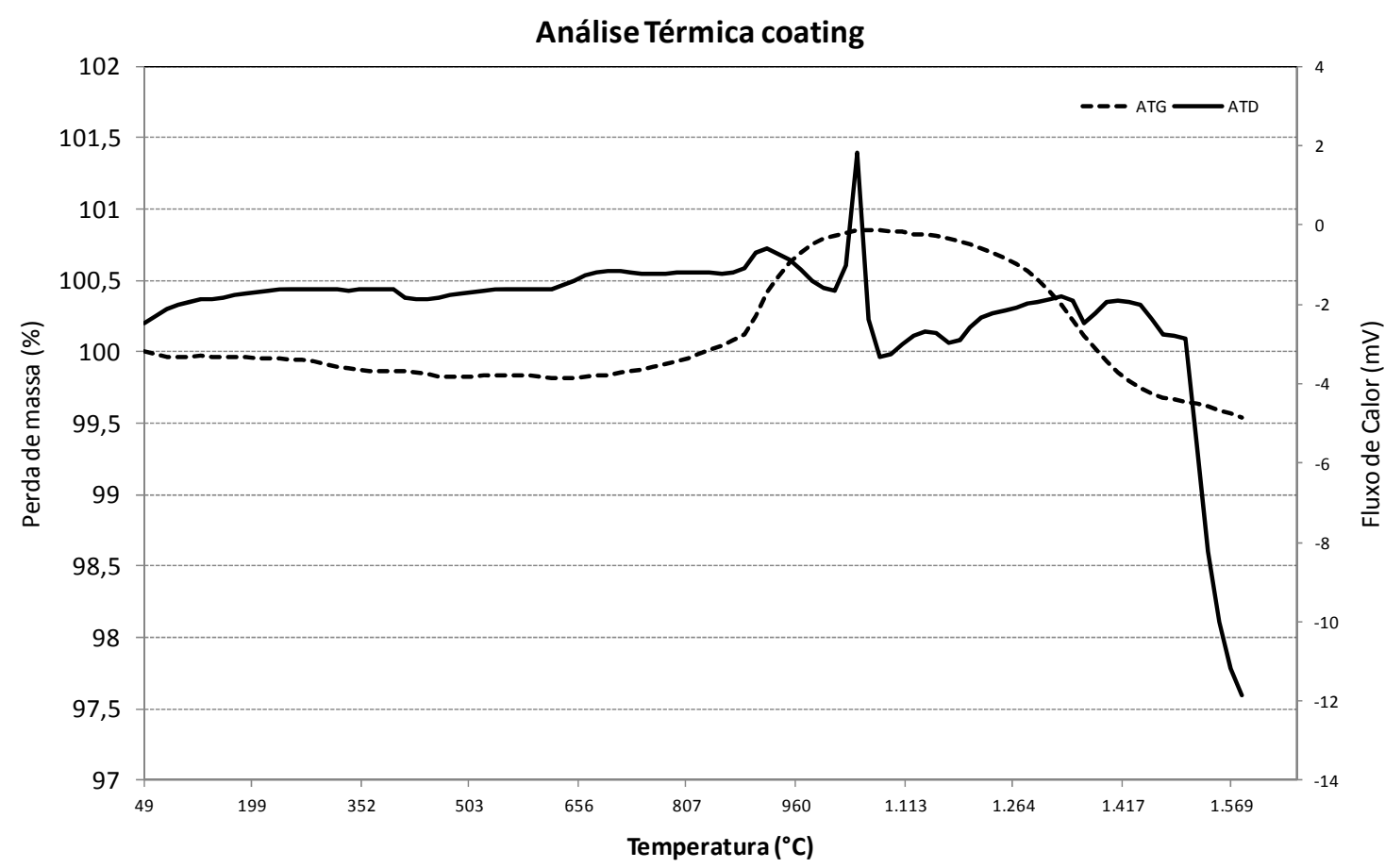

Figura 2. Análise termogravimétrica (ATG) e termodiferencial (ATD) do coating. Atmosfera de ar até a temperatura de $1570^{\circ} \mathrm{C}, 15^{\circ} \mathrm{C} / \mathrm{min}$.

Os resultados da análise térmica (Figura 2) indicam inicialmente uma perda de massa praticamente desprezível $(\sim 0,2 \%)$ e esta pode estar associada à remoção de água superficial. Salienta-se que não há nenhum pico característico de reação endotérmica de perda de água ou de decomposição de alguma fase hidratada. $O$ ganho de massa ocorre a partir de $\sim 850^{\circ} \mathrm{C}$, possivelmente, devido à oxidação de ferro metálico residual na amostra. Esta reação pode ser associada à formação dos

\footnotetext{
* Contribuição técnica ao 45 Seminário de Aciaria - Internacional, 25 a 28 de maio de 2014
} Porto Alegre, RS, Brasil. 
dois picos exotérmicos (900 e $\left.1047^{\circ} \mathrm{C}\right)$, explicando a forte reação de oxidação do ferro metálico presente na amostra.

O decaimento da curva ATD próximo a $1500^{\circ} \mathrm{C}$ ocorre em função do início de formação de fase líquida. A formação da fase líquida nesta temperatura é esperada, pois segundo a literatura [2] as temperaturas solidus e liquidus do $\mathrm{C}_{2} \mathrm{~S}$ puro são de aproximadamente 1464 e $2154^{\circ} \mathrm{C}$, respectivamente. A presença de contaminantes, identificados na análise química (Tabela 1), favorece o aumento da proporção de fase líquida.

A distribuição do tamanho de partículas da amostra STD é apresentada na Figura 3. O diâmetro de partícula médio da amostra é de $11,12 \mu \mathrm{m}$, sendo que $90 \%$ da amostra apresenta tamanho de partícula inferior a 27,16 $\mu \mathrm{m}$. Portanto, o coating tende a ficar numa granulometria bastante fina, ao final da operação e resfriamento da panela à temperatura ambiente.

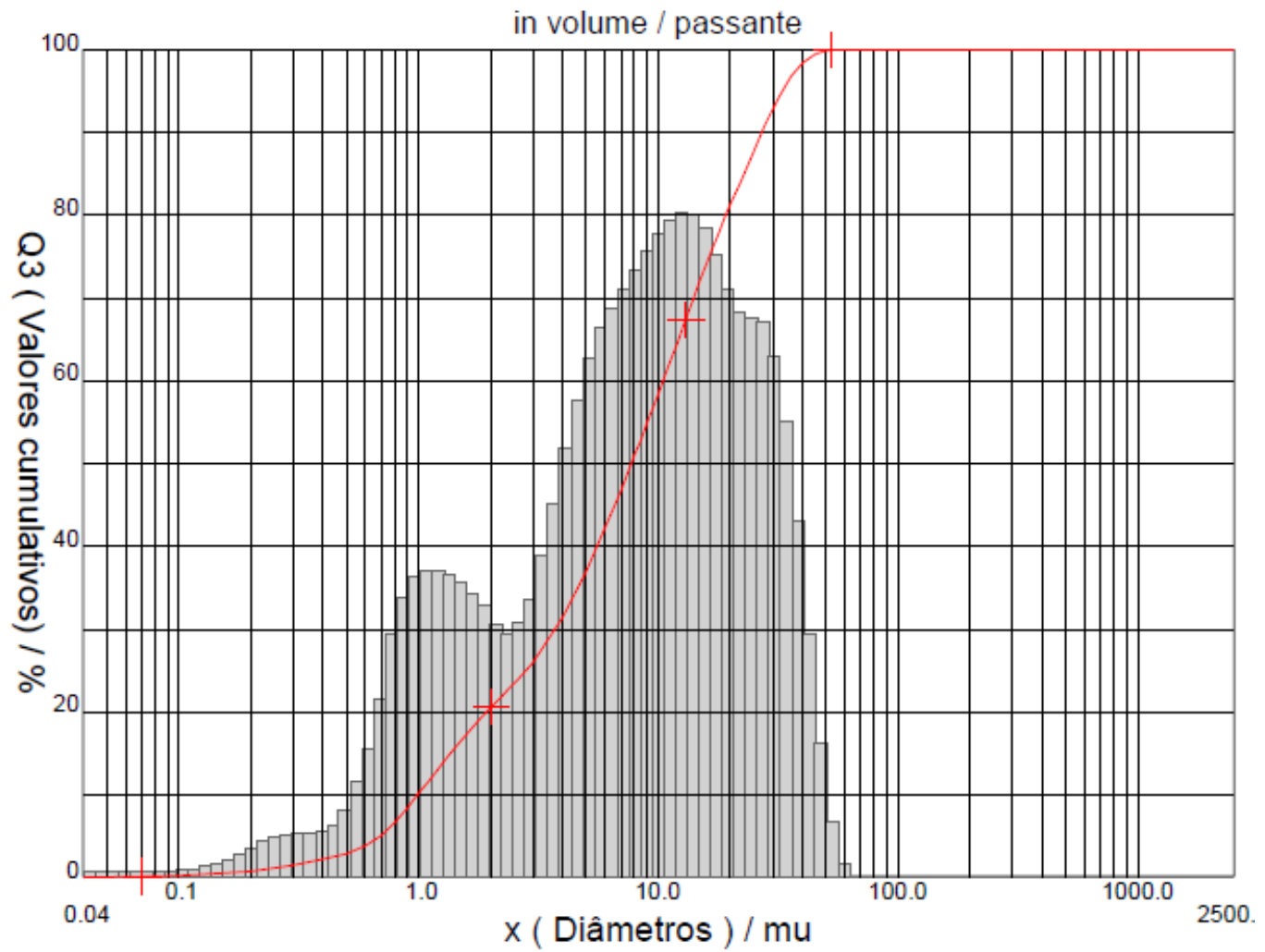

Figura 3. Distribuição de tamanho de partícula acumulado, para a amostra STD.

A análise por difração de raios-X da amostra STD (Figura 4) revela, como fase dominante o silicato dicálcico $\left(\mathrm{Ca}_{2} \mathrm{SiO}_{4}\right)$. Identifica-se também presença das fases periclásio $(\mathrm{MgO})$ e cuspidina $\left(\mathrm{Ca}_{4} \mathrm{Si}_{2} \mathrm{O}_{7} \mathrm{~F}_{2}\right)$. Não foi observada a presença de picos de compostos à base de hidratos e nem a presença de $\mathrm{CaO}$ livre. Compostos hidratáveis poderiam comprometer a integridade do coating devido à expansão volumétrica causada pela hidratação espontânea. É bastante conhecida a transformação da cal livre $(\mathrm{CaO})$ em cal apagada $\left(\mathrm{Ca}(\mathrm{OH})_{2}\right)$ com significativo aumento molar.

\footnotetext{
* Contribuição técnica ao 450 Seminário de Aciaria - Internacional, 25 a 28 de maio de 2014, Porto Alegre, RS, Brasil.
} 

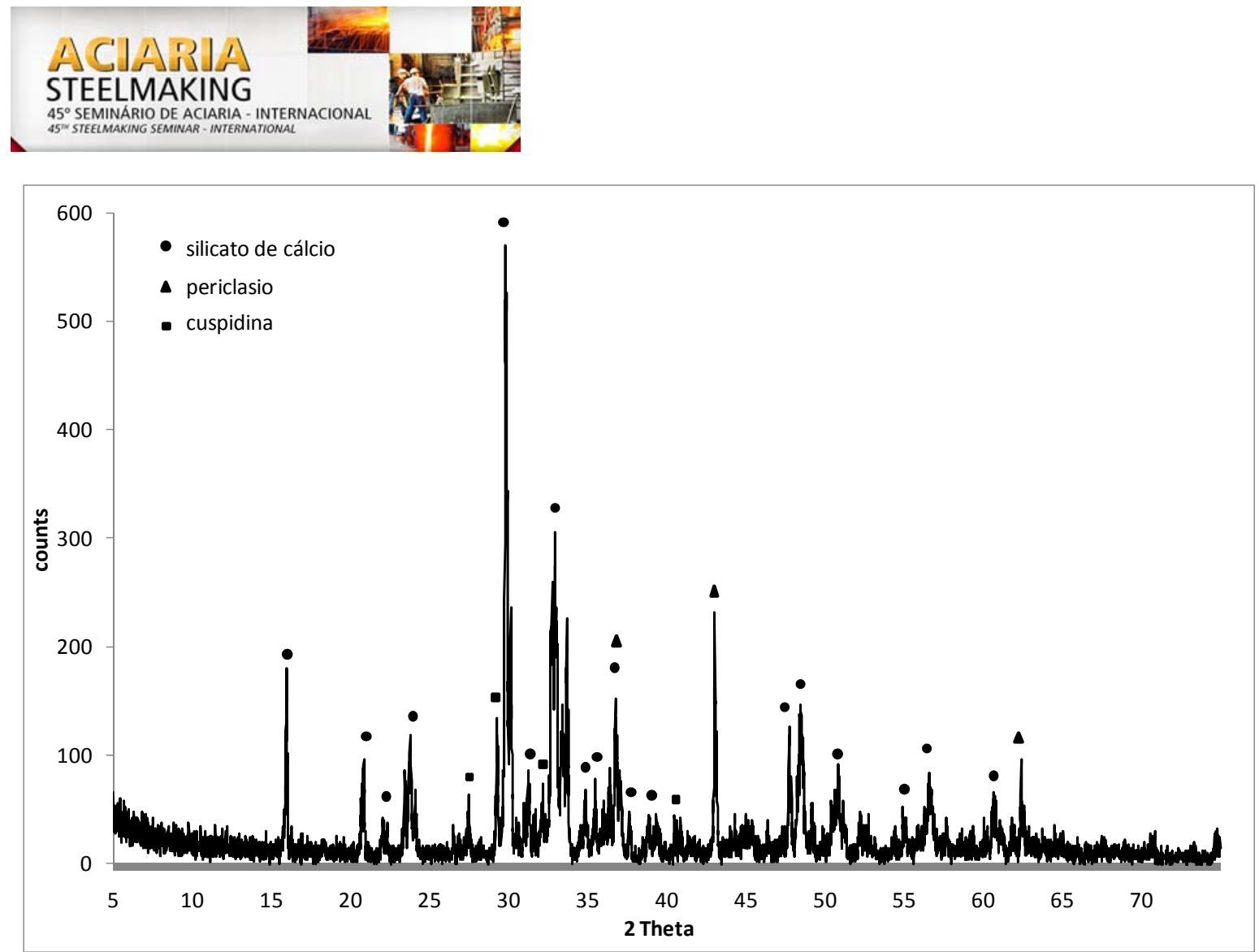

Figura 4. Análise da amostra de coating STD através da técnica de difração de raios-X.

A fim de auxiliar na compreensão da variação dimensional associada ao resfriamento do $\mathrm{C}_{2} \mathrm{~S}$, uma amostra de coating STD foi colocada num forno mufla e aquecida a $1200^{\circ} \mathrm{C}$ (com patamar de 30 minutos). A amostra foi retirada do forno a $600^{\circ} \mathrm{C}$ e resfriada em temperatura ambiente. A Figura 5 apresenta a sequencia de imagens após a retirada da amostra do forno. As imagens da Figura 5 mostram claramente que após 10 minutos (Figura 5b) aparecem trincas grandes que envolvem a estrutura da amostra, de modo que depois de transcorridos 20 minutos (Figura 5c) a amostra está bastante danificada.
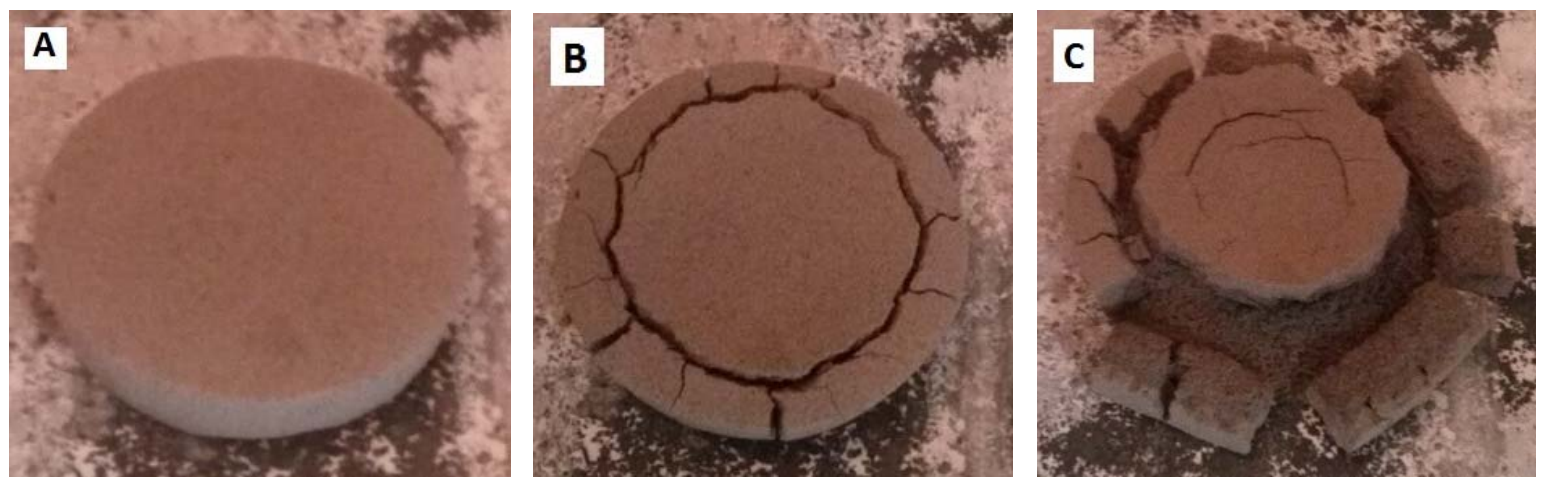

Figura 5. Aspecto visual das amostras do coating STD submetidas à variação de temperatura. Amostras aquecidas a $1200^{\circ} \mathrm{C}$ com 30 minutos de patamar e retiradas do forno a $600^{\circ} \mathrm{C}$. (a) após 5min. (b) após 10min e (c) após 20min.

A Figura 6 mostra as partículas do coating em análise por microscopia eletrônica de varredura. É possível se observar nas áreas em destaque uma estrutura com presença de várias trincas, sendo sua origem provavelmente associada à anisotropia da expansão térmica. Salienta-se que esse efeito de formação de trincas e geração de tensões térmicas, causada pela variação volumétrica, colaboraria ao desprendimento do coating da panela durante o resfriamento da mesma.

* Contribuição técnica ao 45 Seminário de Aciaria - Internacional, 25 a 28 de maio de 2014, Porto Alegre, RS, Brasil. 

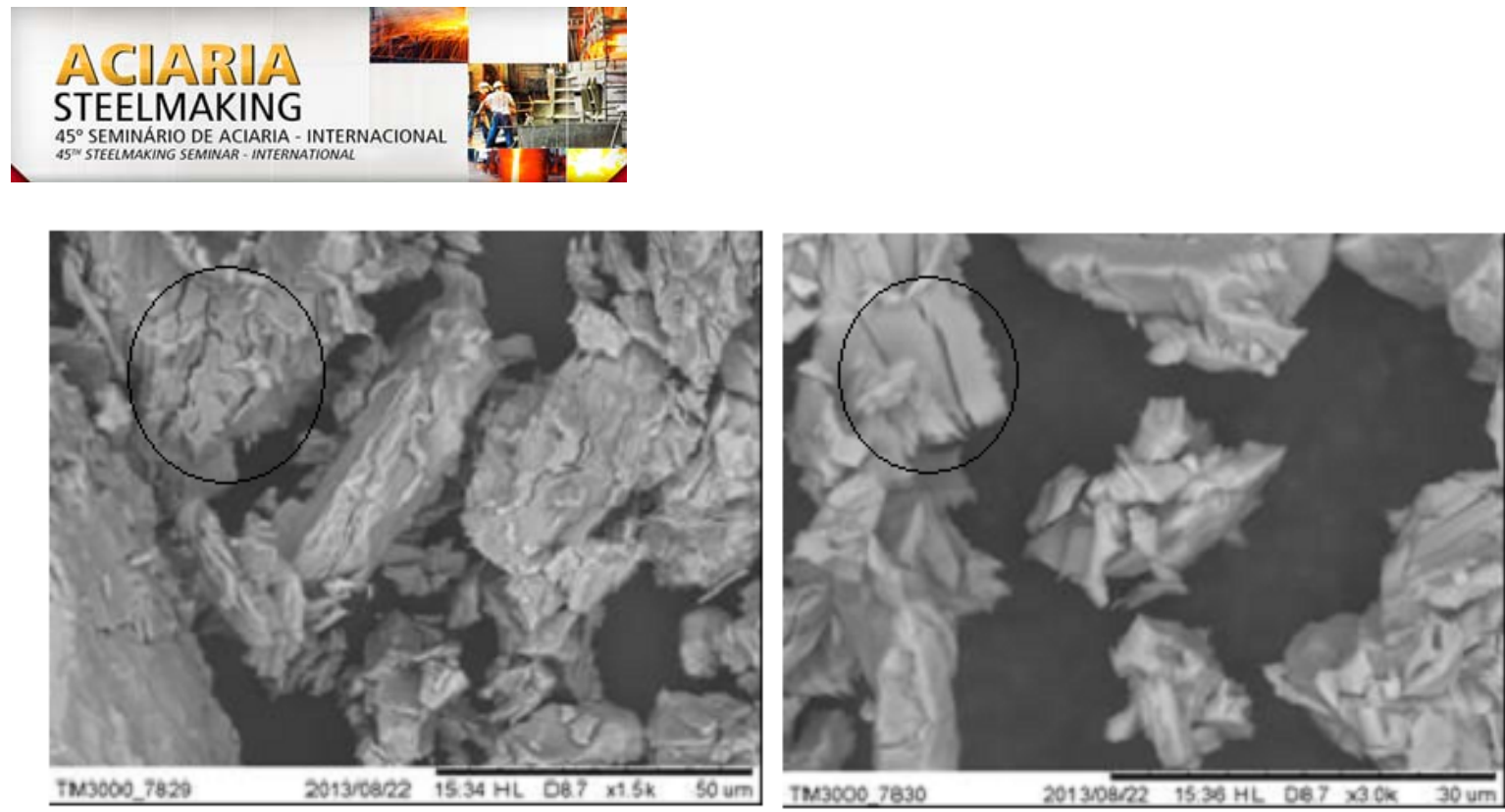

Figura 6. MEV das partículas do coating em diferentes magnitudes. (a) aumento de 1500x e (b) aumento de 3000x. Em destaque trincas de variação da expansão térmica.

Baseado nas análises realizadas, pode-se tentar explicar a perda do coating durante o resfriamento de uma panela. É observado na prática industrial que ocorre o desprendimento do coating dos tijolos da panela no resfriamento, o que diminui a proteção contra a corrosão, em consequência das paradas para manutenção. Os resultados obtidos através das análises de DRX mostram a ausência de fases hidratáveis no coating. A análise em balança térmica (ATG) mostra que a perda de massa é desprezível. Essas duas análises provam que a expansão por umidade não é causa da perda do coating na panela.

No teste realizado em forno mufla, observa-se que ocorre a formação de trincas, provavelmente de origem térmica e que podem estar associadas à reação de inversão polimórfica, como referida na revisão bibliográfico do presente trabalho. Por outro lado, $\mathrm{o}_{2} \mathrm{~S}$, sendo um material de elevada refratariedade (fusão em $\sim 2150^{\circ} \mathrm{C}$ ) não apresentaria significativa ligação entre os grãos, na temperatura do teste da Figura 5, o que explicaria a fácil fragmentação do corpo-de-prova conformado. Mas, neste caso, o aspecto das trincas formadas (Figura 5) e a presença de fratura nos grãos (Figura 6) indicam que a ruptura do corpo-de-prova é, no mínimo, fortemente influenciada pelas tensões térmicas geradas.

\subsection{Estudo de caso: panela retirada de operação por dano aos refratários.}

Para este estudo, as amostras de coating foram removidas de diferentes regiões da panela, como apresentado na Tabela 2.

Tabela 2. Descrição das regiões da panela de aço donde se retiraram as amostras para este estudo de casos

\begin{tabular}{|c|l|}
\hline Amostra & Descrição \\
\hline 1 & Região entre basculamento e munhão \\
\hline 2 & Região próxima ao munhão \\
\hline 3 & Região zona de escória \\
\hline 4 & Região próxima ao basculamento \\
\hline
\end{tabular}

* Contribuição técnica ao 450 Seminário de Aciaria - Internacional, 25 a 28 de maio de 2014, Porto Alegre, RS, Brasil. 
A análise por FRX mostrou uma composição semelhante à amostra padrão (Tabela 1), exceto pelo teor de enxofre, o qual chegou a valores de 2 a 3 vezes maior que o padrão. Este fato ainda está sendo analisado pelos autores.

Com base nas análises comparativas de DRX, Figura 7, constatou-se que as amostras (descritas na Tabela 2) apresentam as fases esperadas, como periclásio, cal, silicato dicálcico e cuspidina.

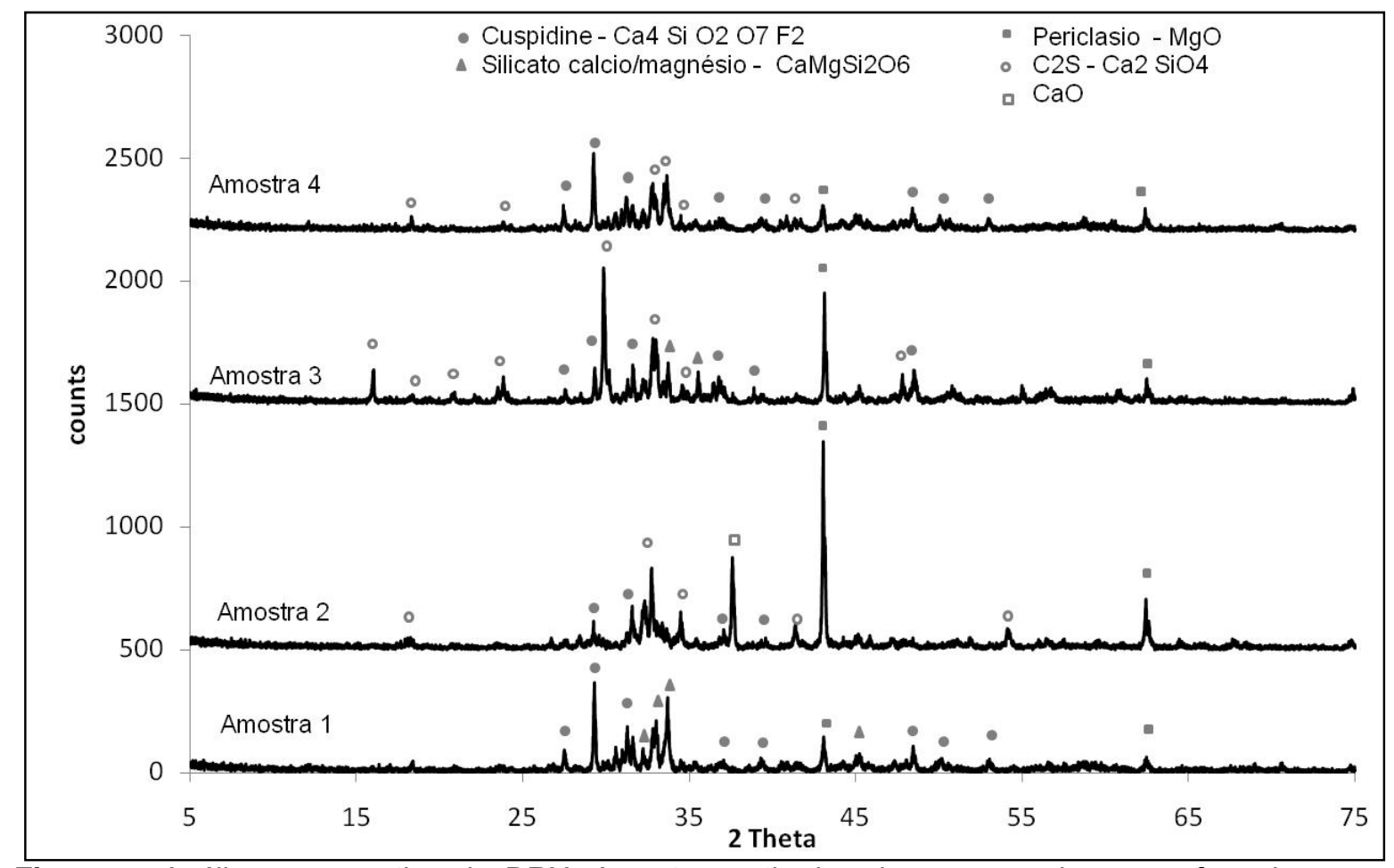

Figura 7. Análise comparativa de DRX. Amostras retiradas de uma panela que sofreu dano nos refratários (Tabela 2).

$\mathrm{Na}$ amostra 1 (Tabela 2) não foi identificada a fase silicato dicálcico $\left(\mathrm{C}_{2} \mathrm{~S}\right)$, no entanto, foi constatada a presença das fases cuspidina $\left(\mathrm{Ca}_{4} \mathrm{Si}_{2} \mathrm{O}_{7} \mathrm{~F}_{2}\right)$, silicato de cálcio e magnésio $\left(\mathrm{Ca}_{7} \mathrm{Mg}\left(\mathrm{SiO}_{4}\right)_{4}\right)$ e periclásio $(\mathrm{MgO})$, sendo que a cuspidina predomina em relação ao periclásio (Figura 7). Esta amostra apresenta um aspecto bastante vitrificado (Figura 8a).
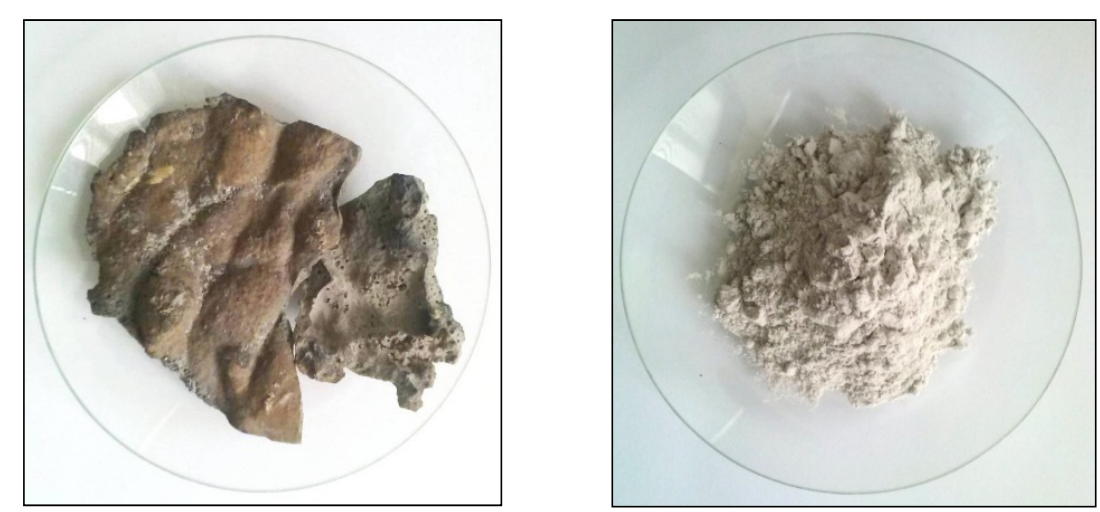

Figura 8. Aspecto visual das amostras de coating. (a) aspecto vitrificado (predomínio da fase cuspidina) e (b) coating conforme seu aspecto característico (predomínio da fase $\mathrm{C}_{2} \mathrm{~S}$ ).

\footnotetext{
* Contribuição técnica ao $45^{\circ}$ Seminário de Aciaria - Internacional, 25 a 28 de maio de 2014, Porto Alegre, RS, Brasil.
} 
Na amostra 2 (Tabela 2) além das fases cuspidina e periclásio foi identificada a presença de $\mathrm{C}_{2} \mathrm{~S}$ (Figura 7 ). Contudo, nesta amostra a fase majoritária é o periclásio e a cuspidina é a fase minoritária. Como a amostra apresentou elevado teor de periclásio, além $\mathrm{Cal}(\mathrm{CaO})$, provavelmente ela tenha sido influenciada pela proximidade (em parte) do tijolo refratário. Se a escória é muito líquida e não há coating ou não está saturada em MgO, vai dissolver mais o refratário aumentando a concentração de $\mathrm{MgO}$.

A amostra 3 (região da zona de escória) apresenta as fases $\mathrm{C}_{2} \mathrm{~S}$, periclásio e cuspidina em sua composição (Figura 7). Neste caso a fase majoritária é o $\mathrm{C}_{2} \mathrm{~S}$ e a fase minoritária é a cuspidina, ocorrendo a completa desagregação da amostra (Figura 8b). Esta amostra apresentou o coating em seu estado característico (conforme amostra STD) com a presença de $\mathrm{C}_{2} \mathrm{~S}$ e periclásio, e apenas pequenos traços da fase cuspidina o que indica apenas uma reação incipiente da escória com do coating.

$\mathrm{Na}$ amostra 4 (Tabela 2) é observada a presença das fases: cuspidina, periclásio e $\mathrm{C}_{2} \mathrm{~S}$, sendo que a fase majoritária é a cuspidina e a minoritária o periclásio (Figura 7). Esta amostra apresentava um aspecto bastante vitrificado, como da amostra 1 (Figura 8a).

A presença de fluorita promove a fusão de escória, como é conhecido. Ao mesmo tempo, ela promove a fusão e provável dissolução do coating, ao formar uma fase de menor temperatura de fusão, como é o caso da cuspidina (temperatura de fusão $\sim 1250^{\circ} \mathrm{C}$ ). $\mathrm{O}$ fato das amostras apresentarem composições de fases diferentes prova que a escória de panela não alcançou uma boa homogeneização, de modo que parte do coating atinge a fusão e parte continua a proteger o refratário de panela.

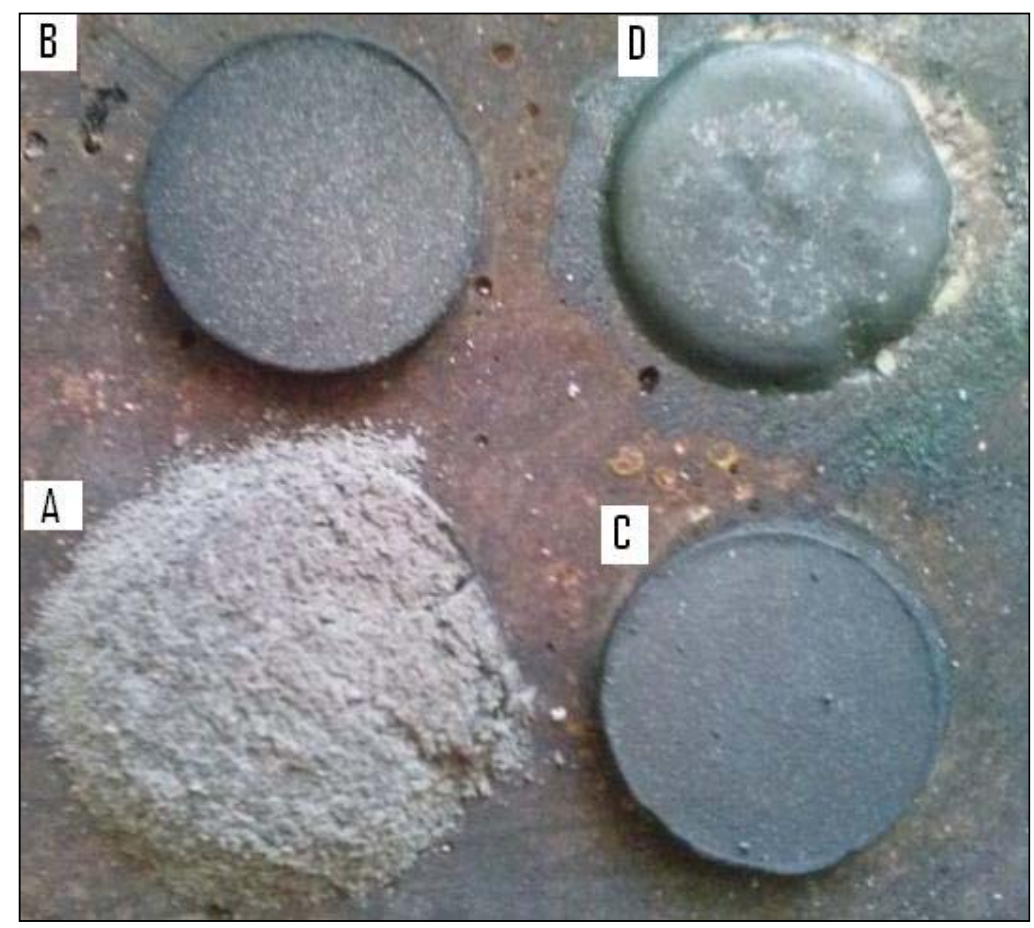

Figura 9. Aspecto visual dos corpos de prova sinterizados a $1400^{\circ} \mathrm{C}$. (a) $100 \% \mathrm{C}_{2} \mathrm{~S}$; (b) $\mathrm{C}_{2} \mathrm{~S}+5 \% \mathrm{CaF}_{2}$; (c) $\mathrm{C}_{2} \mathrm{~S}+10 \% \mathrm{CaF}_{2}$ e (d) $\mathrm{C}_{2} \mathrm{~S}+20 \% \mathrm{CaF}_{2}$.

Ensaios em laboratório, realizados em $1400^{\circ} \mathrm{C}$ mostram que a fluorita promove a fusão ('vitrificação') do coating, como mostra a Figura 9. A composição A (100\%

\footnotetext{
* Contribuição técnica ao 450 Seminário de Aciaria - Internacional, 25 a 28 de maio de 2014, Porto Alegre, RS, Brasil.
} 
$\mathrm{C}_{2} \mathrm{~S}$ ) apresentou fragmentação completa após resfriamento, como observado anteriormente (Figura 5), mas agora em maior temperatura de queima $\left(1400^{\circ} \mathrm{C}\right)$. As amostras B, C e D apresentaram variação dimensional (retração) em função da sinterização promovida pela fluorita, sendo a retração e o aspecto vitrificado crescente em relação ao incremento de fluorita, de modo que a amostra $D$, apresenta-se com as bordas arredondadas e bastante diferentes da forma original. A sinterização do coating foi estudada detalhadamente em outro artigo [6].

\section{CONCLUSÕES}

Em condições normais de processo (amostra STD) o coating é composto principalmente pelo silicato dicálcico $\left(\mathrm{C}_{2} \mathrm{~S}\right)$, periclásio $(\mathrm{MgO})$ e pela fase minoritária cuspidina. Na amostra STD não foi identificada à presença de cal ou portlandita, além disso, a perda de massa apresentada na análise termogravimétrica é praticamente desprezível. Isto prova não ocorrer a hidratação deste material, não sendo esta a causa do desprendimento do coating da panela no resfriamento da mesma em paradas de manutenção. Este fenômeno é mais bem explicado pelas tensões térmicas geradas no resfriamento.

Em condições operacionais de uso intensivo de fluorita, favorece-se a formação de fases de menor temperatura de fusão, como a cuspidina. Por conseguinte, tem-se a dissolução do coating e aumento da corrosão do revestimento refratário por ataque químico pela escória (com elevado teor de fluorita). A análise de amostras em diversas regiões da panela mostra uma composição diferente entre elas. Isto prova uma condição de não equilíbrio, na qual a escória apresenta diferença composicional. Portanto, o aporte de fluorita requer tempo para a mistura e homogeneização da escória na prática industrial. Caso contrário, pode-se criar uma condição que favoreça a corrosão do revestimento refratário.

\section{REFERÊNCIAS}

1 Lee WE, Zhang S. Melt corrosion of oxide-carbon refractories. International Materials Reviews. 1999;44(3):309-320.

2 Eriksson G, Wu P, Blander M, Pelton AD. Critical evaluation and optimization of the thermodynamic properties and phase diagrams of the $\mathrm{MnO}-\mathrm{SiO} 2$ and $\mathrm{CaO}-\mathrm{SiO} 2$ systems. Can. Metall. Q. 1994;33:13-21.

3 Mumme WG, Hill RJ, Bushnell-Wye G, Segnit ER. Rietveld crystal structure requirements, crystal chemistry and calculated powder diffraction data for the polymorphs of dicalcium silicate and related phases. N. Jb. Miner. Abh. Stuttgart. 1995;169:35-68.

4 lan Nettleship, James L. Shull, Jr. \& Waltraud M. Krivenchemical Preparation and phase stability of $\mathrm{Ca}_{2} \mathrm{SiO}_{4}$ and $\mathrm{Sr}_{2} \mathrm{SiO}_{4}$ powders. Journal of the European Ceramic Society. 1993;1:291-298.

5 Gomes S. D. Incorporação de enxofre no silicato dicálcico do clínquer de cimento Portland: influência na estabilidade de polimorfos e na reatividade hidráulica [dissertação de mestrado]. São Paulo: USP; 2007.

6 Da Cruz RT, Pelisser FG, Bielefeldt WV, Bragança SR. Influência da composição da escória de panela na dissolução do coating $\left(\mathrm{C}_{2} \mathrm{~S}\right)$. In: $45^{\circ}$ Seminário de Aciaria Internacional; 2014; Porto Alegre, Brasil. São Paulo: ABM; 2014.

* Contribuição técnica ao 450 Seminário de Aciaria - Internacional, 25 a 28 de maio de 2014, Porto Alegre, RS, Brasil. 